The Original Scientific Article

\title{
ANALYSIS OF ENVIRONMENTAL ASPECTS AT MEAT PROCESSING PLANTS ACCORDING TO ISO 14001
}

\author{
Yulya A. Kuzlyakina*, Zoya A. Yurchak, Baira D. Baskhamdgieva \\ V.M. Gorbatov Federal Research Center for Food Systems of Russian Academy of Sciences, Moscow, Russia
}

\section{KEY WORDS:}

environmental risk, meat industry, assessment of environmental risk, environmental management system, environmental protection

\begin{abstract}
The purpose of this article was to represent the environmental indicators of meat production chain and highlight the main environmental aspects. Meat industry is recognized as one of the leading polluting industries in food production. Meat production chain was analyzed in terms of three levels of environmental aspects: severity of impact, probability, and the calculated quantitative estimate of the emerging aspects. Meat production requires natural resources (water and energy), which leads to the discharge of waste and wastewater. As a result, it has a major impact on climate change, consumption of natural resources and environmental pollution. Future research should focus on the environmental impact of meat production chain in terms of existing and newly developed environmental indicators and on finding solutions to reduce the overall environmental impact.
\end{abstract}

\section{Introduction}

Global changes in the world caused by human impact on the environment are currently leading to the intense destruction of the human environment. Preserving the environment is the main condition for the existence of human civilization [1, 2], and as a result, the main task of processing enterprises.

The current environment is constantly deteriorating. In just a few centuries, we have lost many of their environmental systems and biospheres of great value, along with forever-lost species of plants and animals [3].

Human impact on wildlife continues every day: for the sake of profit, many enterprises cut down forests, pollute lakes, seas and oceans, and slowly destroy the biosphere of the planet $[4,5]$.

This global problem is now in the focus of major world countries and organizations. Many conferences are conducted, and environmental pollution is monitored daily.

«Production ecology» is very extensive term including many theoretical and applied problems, the main purpose of which is to significantly reduce the negative impact of production on the environment. This term covers the particular relationship between the enterprise and the biosphere, as well as environmental problems and methods for solving them. First, the damage to biosphere caused by the production is the emissions of carbon dioxide, which subsequently generates the greenhouse effect and global warming of the planet [6].

The creation of the Kyoto Protocol, which can significantly reduce carbon dioxide emissions worldwide, is the effort of the world's community. Studying the human impact on nature will allow us not only to preserve the primordial natural systems that existed many centuries before us, but also to restore them as much as possible $[7,8]$.

Meat industry is one of the food industries with global environmental impact. This type of production affects climate change in relation to global warming, generates substances that deplete the ozone layer and is characterized by a high water and energy consumption, which leads to the discharge of waste and wastewater. Biosphere pollution including water sources is a real factor that has a negative impact on human health. According to the World Health Organization (WHO), every tenth person in the world suffers every year from the use of low-quality drinking water. Up to $50 \%$ of river water is subjected to human impact every year, including the discharge of 425 x $109 \mathrm{~m} 3$ wastewater.
Significant contamination of water and inefficient water treatment are the main reasons for the low quality of drinking water. Violations of SanPiN2.1.4.10749-01 requirements, in which physical-chemical and microbiological indicators of drinking water are established, are observed in all subjects of the Russian Federation. Over $90 \%$ of wastewater in public utilities are discharged to surface waters in contaminated state. Water quality is significantly affected by the substances and compounds in it in various concentrations. Exceeding the concentration of some pollutants can have a negative effect both on humans and on environment in a water body. Therefore, when discharging wastewater after production, it is necessary to remove harmful substances and achieve maximum permissible concentrations (MPC) of these substances in wastewater [9].

To date, in the field of environmental safety, a series of informational technical handbooks (ITH) has been developed for the best available technologies (BAT), e.g. ITH 8-2015 «Wastewater treatment in the manufacturing of products (goods), works and services at large enterprises»; ITH 22-2016 «Purification of harmful (polluting) emissions into the air in the manufacturing of products (goods), works and services at large enterprises». They are key tools to reduce the negative impact of industry on the environment, which help complying with environmental requirements and promote technological innovation. In addition, ITH 43-2017 «Slaughter of animals at meat processing plants, slaughterhouses, livestock by-products» and ITH 44-2017 «Food production» were developed, which include environmental requirements taking into account the type of industrial enterprises.

So, the BAT ITH 44-2017 «Food production», which is effective since June 1, 2018, contains a description of technological processes used in the production of foods, equipment, technical methods implemented in the Russian Federation, including those that reduce negative impact on the environment and water consumption, increase energy efficiency and resource conservation. From the described technological processes, equipment and technical methods, the solutions are determined that are the best available technologies (BAT).

Of particular note is ITH 43-2017, «Slaughter of animals at meat processing plants, slaughterhouses, livestock by-products», which is also effective since June 1, 2018. This handbook applies to the technology of slaughter and primary processing of cattle, pigs, poultry, etc. In addition, it covers technological processes 
associated with activities that may have or have an impact on the volume of emissions into the environment or the extent of environmental pollution.

Intensification of livestock production creates the conditions for increasing the level of resource consumption and enhancing the negative impact on the environment. This BAT handbook designed to justify decision making on determining available technologies for slaughtering animals at meat processing plants, slaughterhouses, processing livestock by-products, designing new and reconstructing existing meat processing enterprises, and issuing complex permits, discusses solutions to prevent and reduce negative impact of meat processing enterprises on the environment [10].

The implementation of BAT involves large financial investments of the enterprise. However, at the same time, the state plans to support development of these technologies and other measures to reduce negative impact on the environment through a number of measures to provide tax benefits and privileges in relation to fees for negative environmental impact.

Ultimately, the transition to the best available technologies should lead to the modernization of Russian enterprises, which will contribute to the development of ecofriendly and competitive production, as well as minimizing the negative impact on the environment $[11,12,13]$.

Despite the differences in meat production technology, food habits and cultural diversity, ecofriendly and safe production is one of the most serious problems of meat production chain in 21st century [14].

Environmental management is a system for regulating the activities of an enterprise in different forms, directions, etc., which directly or indirectly relate to the enterprise's relationship with the environment [15].

The main goal of environmental management is to increase confidence in the enterprise where it is carried out by systematically improving the environmental situation in all fields of work. The most characteristic improvement is the reduction of the negative impact of industrial enterprises on the environment [16].

Environmental management first appeared in the global economy in 1990s due to the efforts of the International Organization for Standardization (ISO) in accordance with the UN requirements for environmental protection.

One of the first countries to propose environmental management was Great Britain, where in 1990 a new «Environmental Act» was adopted. This document was followed in 1992 by the Specification for Environmental Management System BS7750 prepared and issued by the British Standardization Institute in accordance with the request of the British Industry Conference. It contains recommendations that may be useful for creating an effective environmental management system and developing proactive environmental auditing. This should favorably affect the environment. At the initial stage, it was assumed that UK enterprises would voluntarily follow the recommendations of the BS7750 Standard. Later, other community states joined the UK, and the standard became the basis for the development of regulatory international documents [17].

In accordance with accepted international standards, environmental management system (EMS) is a part of a single management system including organizational structure, activity planning, distribution of responsibility, practical work, as well as procedures, processes and resources for the development, implementation, evaluation of achieved results and improvement of environmental policy.

Most enterprises control their activities in the field of environmental protection, but such control is an internal activity and cannot be considered sufficient to ensure that the activities of enterprises fully meet the requirements of environmental safety.
Currently, a reform is being introduced in the processing industry based on the principles of BAT and technological standardization of enterprises, which was presented on July 21, 2014 by federal law No. 219-FZ «On Amendments to the Federal Law On Environmental Protection». This law divides enterprises into four categories in accordance with the level of environmental impact and the issuance of complex environmental permits (CEP). For the first category, i.e. the most «dirty» plants, the issuance of CEP will be accompanied by the approval of a BAT-based modernization program. Forced introduction of «clean» technologies should lead to a reduction in emissions and discharges, minimize waste generation and result in the gradual closure of obsolete facilities, but taking into account business interests and maximum economic efficiency.

In order to ensure a guaranteed level of environmental protection that meets international requirements and the requirements of national legislation, structured environmental management systems built on certain principles are necessary, which should be combined into general administrative management activities that ensure product competitiveness, financial stability and other economic goals of enterprises in an open market. Such systems should be sufficiently illustrative to ensure that the activities of enterprises not only currently comply, but also will comply with the requirements of environmental safety, i.e. they must ensure the sustainability of enterprises in terms of environmental impact. In particular, such systems are provided by international standards of ISO 14000 series [18].

Environmental management system is determined by its model, which includes five main elements: environmental policy; planning; implementation and operation; inspections and corrective actions; analysis by managers.

The implementation of this model will allow the company to solve the following problems: to identify environmental aspects taking into account past, current or planned activities of the organization, identify regulatory requirements, establish environmental policies and develop structures and programs for its implementation, modify systems against changing circumstances [19].

It is worth noting that one of the main steps towards the implementation of an effective environmental management system is the assessment of environmental risk, which is component of the organization's activities, its products or services and require the adoption of the focused management decisions by identifying possible environmental risks [20].

Management of environmental aspects is aimed at identifying potential violations and risks that need to be eliminated/minimized, as well as at introducing strategies to control such risks.

Thus, risk identification, analysis and management allow enterprises to achieve economic benefits by reducing environmental impact and reducing the use of natural resources, which is an urgent goal today.

\section{Materials and methods}

Given the importance of an effective analysis of environmental risk, the V.M. Gorbatov Federal Research Center for Food Systems of Russian Academy of Sciences conducts research on the management of environmental aspects as part of a model analysis. The object of research is the production process from the slaughter of animals to finished products.

\subsection{Expert assessment methodology}

In the process of implementing an environmental management system in organizations, the question often arises, how to identify significant environmental aspects in order to ensure objective planning when developing and implementing an environmental management system.

As an option for identifying important environmental aspects, a method for ranking their indicators according to the degree of 
environmental impact is proposed. An objective assessment of each indicator of environmental aspects for their subsequent ranking is possible using an expert assessment.

When conducting such studies, the method of aspect scoring is used, i.e. one of the methods of risk assessment based on a generalized indicator determined by a number of expertly assessed values for indicators (factors) of risk level.

The general design of expert surveys includes the following steps:

$\square$ preparation of research, preparation of questionnaires;

$\square$ generation of the goals and issues of expertise;

$\square$ generation of the rules for conducting a survey or the nature of expert relationships;

$\square$ formation of an expert panel;

$\square$ selection of a method for assessing the degree of expert competence;

$\square$ generation of the rules for processing expert opinions;

$\square$ calculation of generalized expert scores, final analysis of expert opinions, interpretation of the results.

\subsection{Methodology for assessing environmental risk}

The identification and assessment of environmental aspects and environmental impact of an enterprise is carried out according to the main activities of the enterprise.

To determine the level of impact on the environment, a list of environmental aspects of the entire production process is created and the level of impact is determined according to the scale: A) Low «1» - a slight impact on the environment is expected; B) Medium «2»-limited or medium impact on the environment; C) Significant $« 3 »-$ significant impact on the environment.

The determination of environmental aspects with a detailed development of the environmental impact diagram is carried out for those production processes that have at least one significant level of environmental impact (score 3).

Based on the experience and analysis of technological documentation for the process, technical and sanitary-hygienic certificates for equipment, environmental aspects are determined for which there is a possibility of environmental impact, as well as the loss of raw materials and energy. The identification of important and priority aspects is based on their systematic assessment.

If an aspect have positive answers to one of the two questions below, then it is ranked as priority aspect:

1. The aspect does not meet the requirements of legislative acts;

2. The aspect is contrary to the environmental policy of the enterprise.

All other aspects are evaluated according to the method of assessing the significance.

To determine the significance, three levels of environmental aspects are distinguished, i.e. the severity of impact, the probability and the calculated quantitative estimate of the emerging aspects.

The significance is defined as the sum of the severity of impact, the probability and the calculated quantitative estimate of the emerging aspects.

The severity of impact is defined as the sum of positive answers to the following questions (maximum score is 7):

1. May this aspect adversely affect the organization's reputation if there is no control over it?

2. Is this aspect related to soil pollution in the region?

3. May this aspect lead to water pollution?

4. Is this aspect related to the impact on air quality in the region?

5. Is this aspect related to the impact on global warming?

6. Is this aspect related to the impact or risk to public health?

7. Does this aspect generate waste?
The probability of environmental aspects and the calculated quantitative estimate are evaluated in accordance with the scores given in Table 1.

Table 1

Probability criteria and the calculated quantitative estimate of environmental aspects.

\begin{tabular}{|c|c|c|}
\hline The probability & Score & $\begin{array}{l}\text { The calculated quantitative estimate } \\
\text { of environmental aspects }\end{array}$ \\
\hline at least every day & 4 & significant aspect nationwide \\
\hline at least every week & 3 & significant aspect throughout the enterprise \\
\hline at least monthly & 2 & $\begin{array}{l}\text { insignificant, but one that has an } \\
\text { accumulating property }\end{array}$ \\
\hline at least annually & 1 & $\begin{array}{l}\text { insignificant and does not have an } \\
\text { accumulating property }\end{array}$ \\
\hline
\end{tabular}

The values of the selected scores of each of the four levels of environmental aspects are presented in in columns 5 to 7 of the environmental aspects table (Table 3).

The overall significance of environmental aspects $\left(K_{\text {sig }}\right)$ is determined by the sum of the significance scores for all levels of aspect manifestation according to the following equation:

where

$$
K_{\text {sig }}=\sum_{i=1}^{i=N} X_{i},
$$

$X_{i}$ is the estimated significance score of level $I\left(X_{i}=1,2,3\right)$;

$N$ is the number of levels $(N=3)$.

The value of Ksig varies from 3 to 15 .

After the calculations are completed, the values of $K_{\text {sig }}$ are displayed in column 8 of the environmental aspects table (Table 3).

The results of the overall significance are displayed as letter indexes (I, S) in column 9 of the environmental aspects table (Table 3).

The overall (integral) significance of environmental aspects is determined in accordance with Table 2.

Overall significance scores of environmental aspects Table 2

\begin{tabular}{cccc}
\hline \multicolumn{2}{c}{ Aspect category } & \multirow{2}{*}{$\boldsymbol{K}_{\text {sig }}$ value } & Additional conditions \\
\cline { 1 - 4 } Index & Name & & No significance \\
\hline I & Insignificant & $3-7$ & Significance level \\
\hline S & Significant & $8-15$ & \\
\hline
\end{tabular}

\section{Results and discussion}

Using the described methodology, in accordance with the block diagram of the production process for each technological stage, environmental aspects and their significance are determined. An example of assessment for the «Slaughter» stage is presented in Table 3.

Identification and assessment of environmental aspects are carried out by the main activities of the enterprise. Throughout the entire production cycle, production activities include a number of technological processes, from the receipt control of raw materials to storage of finished products, as well as all related production stages, that may lead to environmental risk.

Assessment of environmental impact is reviewed as part of the annual auditing of the environmental management system; in case of changes in the organizational structure of the enterprise; or in case of changes in the structure of processes, activities, in the list of applicable laws and regulations; as a result of the environmental events, complaints and claims from interested parties; or identification of inconsistencies during internal and external auditing, but at least once a year.

Based on the resulting data, a diagram (Figure 1) of the process with certain categories of environmental aspects was built. 
Table 3. The results of environmental aspects analysis for the «Slaughter» stage

\begin{tabular}{|c|c|c|c|c|c|c|c|c|}
\hline 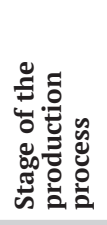 & Environmental aspects & 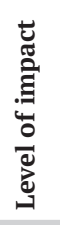 & Description of environmental aspects & 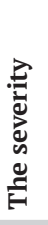 & 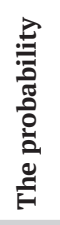 & 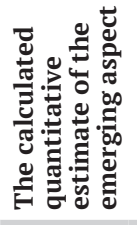 & 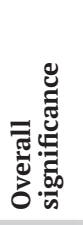 & 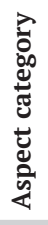 \\
\hline 1 & 2 & 3 & 4 & 5 & 6 & 7 & 8 & 9 \\
\hline \multirow{9}{*}{ 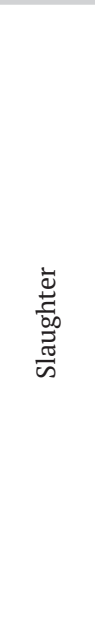 } & Emissions to air (including overlimit) & 3 & $\begin{array}{l}\text { - Emission of odors from the storage and processing } \\
\text { of blood and wastewater treatment plants } \\
\text { - Emissions of dust into the environment. } \\
\text { - Vent exhaust, especially from slaughter waste } \\
\text { processing workshops requiring purification }\end{array}$ & 4 & 1 & 3 & 8 & S \\
\hline & $\begin{array}{l}\text { Industrial and household waste generation, } \\
\text { including by-products. }\end{array}$ & 3 & $\begin{array}{l}\text { - Biological waste (meat and bone waste, blood, } \\
\text { hair, paunch content, manure from pre-slaughter } \\
\text { areas) } \\
\text { - Solid household waste }\end{array}$ & $\begin{array}{l}6 \\
6\end{array}$ & $\begin{array}{l}4 \\
4\end{array}$ & $\begin{array}{l}4 \\
4\end{array}$ & $\begin{array}{l}14 \\
14\end{array}$ & S \\
\hline & High water consumption & 3 & $\begin{array}{l}\text { - The consumption of water, steam and ice for } \\
\text { technological purposes }\end{array}$ & 6 & 4 & 5 & 15 & S \\
\hline & Contaminated industrial and surface discharges & 3 & $\begin{array}{l}\text { - Discharge of pollutants from the enterprise's } \\
\text { wastewater into a water body }\end{array}$ & 5 & 3 & 4 & 12 & S \\
\hline & Negative effects on the human body (accidents) & 3 & \multirow{5}{*}{$\begin{array}{l}\text { - Use of energy resources } \\
\text { - Water use } \\
\text { - Noise from animals during unloading and sorting, } \\
\text { as well as from work of compressor installations } \\
\text { - Fires }\end{array}$} & 3 & 1 & 3 & 7 & I \\
\hline & Noise impact & 3 & & 1 & 1 & 4 & 6 & I \\
\hline & Odors & 3 & & 1 & 3 & 3 & 7 & I \\
\hline & Electric current & 3 & & 2 & 3 & 3 & 7 & I \\
\hline & Heat exposure (fires) & 3 & & 2 & 2 & 3 & 7 & I \\
\hline
\end{tabular}

As a result of the diagram analysis based on the sum of significant and insignificant environmental aspects of each production stage, it was found that the stages of slaughter, deboning, trimming and the production process itself have the most negative impact on the environment, which is due to:

1. the formation of biological and solid waste at the stages of slaughter, removal of offal and cutting of raw materials that requires disposal and processing;

2. the formation of streams with off-odor during slaughter and cutting of carcasses;

3. the presence of wastewater in the process of slaughter and classification of raw materials and during auxiliary operations of equipment, containers, inventory and premises treatment requiring a mandatory purification in any direction of water disposal (urban sewage or water body), as well as disinfection when discharged into the natural environment;

4. the formation of liquid wastes from wastewater treatment (sludge, sediment) requiring dehydration before their transition to landfills;
5 high energy consumption associated with meat refrigeration, water heating, heat treatment of by-products (fat refining, production of gelatin, glue, meal);

6. possible contamination by bacteria, spoilage of the product during improper storage;

7. environmental pollution with toxic antiseptics.

To reduce the degree of impact on the environment and human health, corrective actions have been developed for the «Slaughter» stage to eliminate non-compliance and prevent its recurrence, which are presented in Table 4.

All significant risks and corrective actions are represented in the environmental goals of the enterprise, environmental program and tasks depending on their level and complexity.

Each assessment must take into account direct and indirect risks that are associated with routine and emergency situations. Direct risks, as a result of which there is a direct impact on the environment (emissions, discharges, waste, noise, etc.), and indirect risks, when the impact is mediated through other organizations (consumption of energy produced at power plants, consumption of water from centralized water supply sources).

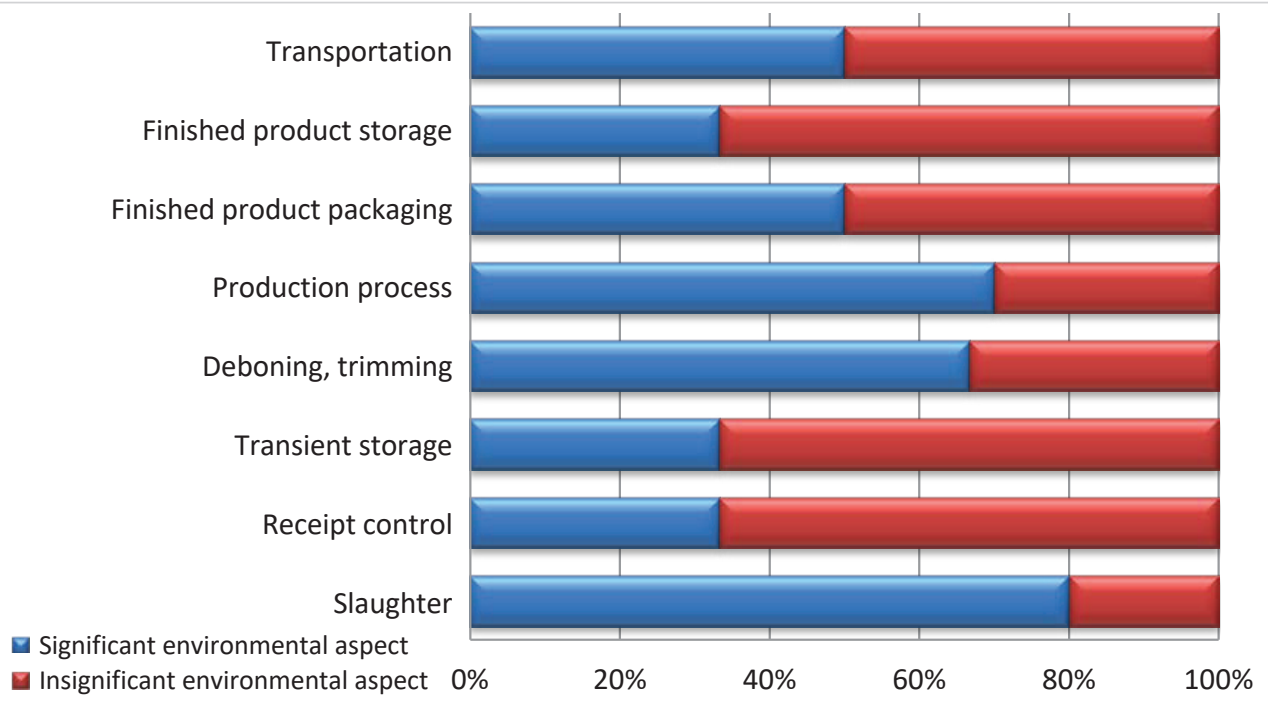

Figure 1. Categories of process environmental aspects 


\section{Corrective actions for identification of environmental risk for the «Slaughter» stage}

Table 4

Environmental risk (aspect)

The formation of biological waste at the stages of slaughter, deboning, trimming, and evisceration of raw materials

Solid waste generation from the manufacturing process

Wastewater generation

Energy use

Water use

Off-odor at work

The appearance of harmful bacteria in the product

\section{Corrective actions}

Processing waste approved by the veterinary service for processing into animal feed;

Use of waste as raw material for biogas production;

Disposal of waste by disinfection in biothermal pits, incinerating or removal under an agreement with biological waste utilization companies.

Increased responsibility for solid waste processing;

Waste processing into secondary raw materials. Garbage goes to processing and turns into thermal energy and organic fertilizer. The use of environmentally friendly, photodegradable polymer packaging materials.

Complete separation of the non-food waste processing line.

Reduction of water level in blood by steam coagulation before processing.

The use of improved filtration systems, flotator for fine deep wastewater treatment;

The use of mechanical and physical-chemical water treatment.

The use of grease traps with automatic collection and removal of grease sludge and sediment.

Biological wastewater treatment, including selective tank, denitrifier, aeration tank/nitrifier, sludge flotator, biological aerobic reactor, sludge tank and unit for the preparation and dosing of nutrients.

Wastewater treatment using lignosulfonic acid (LSA), i.e. removal of coarse suspended matter on gratings and in sand traps, averaging of drain, mixing of liquid with reagents, flotation, neutralization of treated water.

Treatment of manure- and paunch manure-containing wastewater.

Cleaning and disinfection of infected drains with manure trap.

Equipping cattle pens in meat processing plants with protective canopies, since rainfall increases the amount of wastewater.

Using grease traps to remove fat from water.

Identification of problem areas of electricity overruns and determination of measures to eliminate it;

Measures to update production equipment (improvement in cold supply systems);

Measures to update lighting equipment.

The use of centrifugal fans (with reverse bending) in ventilation and refrigeration systems.

The use of water sprayers (cooling with liquid curtain) or shock freezing (rapid cooling tunnels) for cooling animal carcasses.

The use of dry scraper to clean livestock vehicles before high pressure hose washing. Minimize washing of carcasses in combination with clean slaughter methods, while avoiding washing in cases where it is acceptable.

Removing all unnecessary taps from the slaughter line.

Hot water management and process control.

Wash pigs with a timer-controlled nozzle to save water.

Dry cleaning of the floor in the pen for slaughtering livestock and its periodic washing with water.

Reuse of cold water from pork scrapers and replacing irrigation pipelines with flat nozzles.

Reuse of cooling water from pig burning furnaces.

Pig washing after burning using a flat nozzle.

Adjustment and minimizing the water consumption while washing small and large intestines.

Adjustment and minimizing the water consumption while washing tongues and hearts.

Creation of more effective treatment facilities; verification of ventilation and exhaust systems.

Increasing control over temperature conditions of product storage at all stages of production; prevention of raw materials excesses.
In all cases, when possible, a quantitative assessment of influences will be performed with the definition of methods for its implementation and control.

According to Takwa Aloui [21], the main sources of emissions from cattle rearing and slaughter are enteral fermentation, manure management and energy consumption. In particular, the main greenhouse gases (GHGs) emitted by this industry are methane $\mathrm{CH}_{4}$ (greenhouse gas associated with animal emissions), nitrous oxide $\mathrm{N}_{2} \mathrm{O}$ (the most powerful greenhouse gas) and carbon dioxide $\mathrm{CO}_{2}$.

Andrien [22] notes that according to the CAPRI model, the agricultural sector emits $49 \%$ of total GHGs, while $21 \%$ comes from the energy sector, $2 \%$ from the industrial sector and $29 \%$ from changes in land use. With regard to livestock, European livestock emits a total 661 million tons of $\mathrm{CO}_{2}$-eq., which is distributed as follows: $29 \%$ from the production of beef, $29 \%$ from the production of cow's milk, 25\% from the production of pork, and 17\% from all other animal products. Therefore, Pelletier and Tyedmers report that direct GHG emissions from meat, milk and egg production are predicted to increase by $39 \%$ in 2050 compared to 2000 [23].

\section{Conclusion}

Studies have shown that during meat processing, the stages of slaughter, deboning, trimming and the production process itself have the most negative impact on the environment. The main ways to reduce this impact of meat production on environmental safety are identified, which include the need to implement ways to improve the management of meat production aimed at producing high-quality meat that meets the principles of meat quality management at low cost. The best solutions also include introduction of best environmental practices in areas with livestock farms, proper location and construction of meat livestock farms, reducing the amount of biological waste, disposal of waste in the safest way, reducing the amount of water consumption and improving the quality of wastewater.

\section{REFERENCES}

1. Samoilova, N.A. (2014). Environmental management: study guide. Kemerovo: KemTIPP. - 184 p. (in Russian)

2. Umair S (2015) Global Warming: Causes, Effects and Solutions. Durreesamin Journal, 1,4 .

3. Nikitin, A.T., Gordienko, V.A., Dezhkin, V.V., Moiseev, N.N. (2000). Ecology, environmental protection, environmental safety. Moscow: Nov. - 648 p. ISBN 5-7383-0124-2 (in Russian)
4. Chernova, N.M., Bykova, A.M., (2004). General ecology: Textbook for students of pedagogical high schools. Moscow: Drofa. -416 p. ISBN 5-7107-7427-8 (in Russian)

5. Bannikov, A.G., Vakulin, A.A., Rustamov, A.K. (1996). Basics of ecology and environmental protection. Moscow: Kolos, -304 p. (in Russian)

6. Predelskiy, L.V., Korobkin, V.U., Prikhodchenko, O.E. (2009). Ecology: Electronic textbook. Textbook for high schools. Moscow: Knorus. ISBN-13(ean) 9785390002896 (in Russian) 
7. Piskulova, N.A. (2006). Kyoto Protocol: opportunities for Russia. A set of training materials for the program of the course «State Environmental Management». Moscow: MGIMO. - 88 p. (in Russian)

8. Steinfeld, H., Gerber, P., Wassenaar, T., Castel, V., Rosales, M., de Haan, C. (2006) Livestock's Long Shadow: Environmental Issues and Options. Renewable Resources Journal, 24(4), 15-17.

9. ITS43-2017 Slaughter of animals at meat-packing plants, meat-slaughterhouses, livestock by-products.

10. Fedorenko, V.F. (2017). Using the principle of the best available technologies for the modernization of livestock. Bulletin of VNIIMZH,2(26), 49-55. (in Russian)

11. Belokrylova, E.A., Uage, M.B. (2014). Best available techniques in Russian environmental law: problems and prospects. Bulletin of Udmurt University. Series Economics and Law, 4,119-123. (in Russian)

12. Kuzlyakina, Yu. A., Yurchak, Z.A., Frolova, M.G. (2018). Legislative requirements in the meat industry within the framework of ecological safety. Meat Industry, 6, 29-33. (in Russian)

13. Kuzlyakina, Yu.A., Yurchak, Z.A., Frolova, M.G. (2017). Prospects for the introduction of environmental management at Russian meat companies. Vsyo o myase, 6, 29-31. (in Russian)

14. Trifu, C., Petroman, I., Petroman, C., Marin, D., Ivu, M., Peţ, I., Popescu, J. Pîrvu, M. (2011). Evolution and current situation of cattle breeding in our country. Lucrări Ştiinţifice, Seria I, Management Agricol, 13, 2, $311-318$.
15. Environmental management system at the enterprise. [Electronic resource http://www.b-energy.ru/biblioteka/ekologiya-konspekt-lekcii/458-sistema-ekologicheskogo Access date 20.06.2019]

16. Babina, Yu.V., Varfolomeeva, E.A. (2002). Environmental management. Moscow: Perspektiva. -207 p. ISBN 5-88045-062-7 (in Russian)

17. Pakhomova, N., Enders, A., Rikhter, K. (2003). Environmental management: Textbook for high schools. St. Petersburg: Piter. - 544 p. (in Russian)

18. Belov, G.V. (2006). Environmental management at the enterprise - study guide. Moscow: Logos. - 240 p. (in Russian)

19. Bobrov, A.L. (2009). The Concept and Prerequisites for Development of Environmental Management. Bulletin of the Moscow University. Series 6: Economics, 5, 114-120. (in Russian)

20. Okazova, Z., Valery Basiev, V., Doev, D.. (2012) Environmental aspects of industrial production. Industry. Ecology. Person. M: LAP LAMBERT Academic Publishing. - 232. 7 (in Russian)

21. Takwa, A., M'hamdi, N., Bouraoui, R., M'hamdi H., Hechlef, H., Mouna, H (2018). Journal of Dairy \& Veterinary Sciences, December,06, 1-7

22. Adrian L, Tom W, Francesco NT, Suvi M (2010) Evaluation of the livestock sector's contribution to the EU greenhouse gas emissions (GGELS)-Final report. Joint research centre-European commission.

23. Pelletier, N., Tyedmers, P. (2010) Forecasting potential global environmental costs of livestock production 2000-2050. Proceedings of the National Academy of Sciences of the United States of America, 107(43),1837118374. DOI: $10.1073 /$ pnas.1004659107

\section{AUTHOR INFORMATION}

Yulya A. Kuzlyakina - candidate of technical sciences, senior research, Department of technical regulation and food safety systems, V.M. Gorbatov Federal Research Center for Food Systems of Russian Academy of Sciences

109316, Moscow, Talalikhina str., 26. Tel.: +7-495-676-35-29 E-mail: yu.kuzlyakina@fncps.ru *corresponding author

Zoya A. Yurchak - candidate of technical sciences, head of department, Department of technical regulation and food safety systems, V.M. Gorbatov Federal Research Center for Food Systems of Russian Academy of Sciences

109316, Moscow, Talalikhina str., 26. Tel.: +7-495-676-35-29 E-mail: z.yurchak@fncps.ru

Baira D. Baskhamdgieva - senior tecnician, Department of technical regulation and food safety systems, V.M. Gorbatov Federal Research Center for Food Systems of Russian Academy of Sciences

109316, Moscow, Talalikhina str., 26. Tel.: +7-495-676-35-29 E-mail: b.bashamdzhieva@fncps.ru

Authors are equally relevant to the writing of the manuscript, and equally responsible for plagiarism

The authors declare no conflict of interest

Received 10.07.2019 Accepted in revised 09.09.2019 Accepted for publication 15.09.2019 